\title{
Preparing for the new age of the Nagoya Protocol in scientific ocean drilling
}

\author{
Nan Xiao ${ }^{1}$, Naokazu Ahagon ${ }^{1}$, Yusuke Kubo ${ }^{2}$, and Hajimu Morioka ${ }^{3}$ \\ ${ }^{1}$ Kochi Institute for Core Sample Research, Japan Agency for Marine-Earth Science and Technology \\ (JAMSTEC), Monobe B200, Nankoku, Kochi 783-8502, Japan \\ ${ }^{2}$ Center for Deep Earth Exploration, JAMSTEC, 3173-25, Showa-machi, Kanazawa-ku, Yokohama-city, \\ Kanagawa, 236-0001, Japan \\ ${ }^{3}$ National Institute for Environmental Studies (NIES) 16-2 Onogawa, Tsukuba, Ibaraki, Japan \\ Correspondence: Nan Xiao (nanxiao@jamstec.go.jp)
}

Received: 12 July 2018 - Revised: 20 September 2018 - Accepted: 27 September 2018 - Published: 22 October 2018

\begin{abstract}
Deep biosphere research has become one of the major scientific focuses in ocean drilling science. Increased scientific attention to microbiological research of the subseafloor environment raises the complications and concerns related to adherence to the Nagoya Protocol of the Convention on Biological Diversity (CBD). The Nagoya Protocol's implementation has prompted new legislation that could change international collaborative research on the geomicrobiology of the subseafloor. In this paper, we summarize the central points of the Nagoya Protocol on access and benefit-sharing (ABS) and discuss their relationship to ocean drilling research. In addition, we addressed the challenges faced by ocean drilling in complying with this international convention.
\end{abstract}

\section{Introduction}

In recent decades, deep life has become one of the major research themes of scientific ocean drilling. An increasing number of expeditions have conducted fruitful deep biosphere research. Cross-national collaboration in the field is very common, as most ocean drilling expeditions are conducted via international programs (Oldham et al., 2014). Since the adoption of the Nagoya Protocol, the legality of using genetic resources obtained through drilling core samples for research, especially in international collaborations, requires reconsideration. Prior to the commencement of the Convention on Biological Diversity (CBD) in December 1993, biological samples were relatively easy to use for research purposes. Previous regulations primarily focused on customs control for taxation purposes, or plant quarantine guidelines to prevent the introduction of undersired species. Both types of regulations also applied to core samples obtained from land, when the samples were transferred abroad after drilling. Samples obtained from drilling in the ocean, however, were not subject to either type of regulation.
The Nagoya Protocol on Access to Genetic Resources and the Fair and Equitable Sharing of Benefits Arising from their Utilization, known by its simplified name "the Nagoya Protocol", was approved by the Conference of the Parties to the CBD in October 2010 (Table 1). The CBD was drafted and agreed upon by the United Nations Conference on Environment and Development and was signed by diverse parties throughout the world. The vast majority of the world's governments committed to abiding by and enforcing the CBD. The aim of the CBD is to promote "sustainable development" of biological diversity, namely "meeting our needs while ensuring that we leave a healthy and viable world for future generations" (Secretariat of the Convention on Biological Diversity, 2010). After discussion and negotiation for over 10 years by multiple working groups mandated by the CBD, the Nagoya Protocol was adopted in 2010, and entered into force on 12 October 2014, 90 days after the 50th instrument of ratification was deposited (see the Nagoya Protocol website in Table 1). As of the end of May 2018, 92 countries have become signatories and 105 countries have ratified the Nagoya Protocol (Table 1). 
Table 1. Useful URL links are provided for scientists to seek detailed information. Abbreviations are listed in Appendix A.

\begin{tabular}{ll}
\hline $\begin{array}{l}\text { Useful links to seek } \\
\text { information }\end{array}$ & \\
\hline CBD & https://www.cbd.int/ \\
Nagoya Protocol & https://www.cbd.int/abs/ \\
The Bonn Guidelines & https://www.cbd.int/doc/publications/ \\
cbd-bonn-gdls-en.pdf & https://absch.cbd.int/ \\
ABS Clearing-House & http://www.wfcc.info/index.php/guidelines/ \\
WFCC Guidelines & https://www.iodp.org/ \\
IODP & http://www.kochi-core.jp/DeepBIOS/ \\
DeepBIOS website in KCC & http://www.iodp.org/resources/ \\
IODP sample database for & access-data-and-samples \\
microbiological samples & https://eur-lex.europa.eu/legal-content/EN/ALL/?uri= \\
ABS regulation in the EU & celex:52012SC0292 \\
& http://www.env.go.jp/nature/biodic-abs/english.html \\
ABS Guidelines in Japan & http://www.un.org/Depts/los/convention_agreements/ \\
UNCLOS & texts/unclos/UNCLOS-TOC.htm \\
&
\end{tabular}

As one the CBD's three main established goals, the Nagoya Protocol specified the utilization of genetic resources. The Nagoya Protocol affirmed states' sovereign right to control the utilization of their genetic resources. In particular, by establishing more predictable conditions for accessing genetic resources, the Nagoya Protocol improved legal certainty and transparency for both resource providers and users. The document also helps to ensure benefit sharing when genetic resources leave the country of origin. Finally, the protocol lays out core obligations for its contracting parties to take measurements related to genetic resource access, benefit sharing, and compliance. Under the Nagoya Protocol, obligations to share benefits require potential users to seek prior informed consent (PIC) and negotiate mutually agreed terms (MATs) with the provider's government or local individuals. The Bonn Guidelines on access and benefitsharing (ABS), drafted by the secretariat of the $\mathrm{CBD}$, provide information on the terms that must be negotiated between the user and provider, and recommend the contents be finalized in MATs (Table 1). Contracting parties of the Nagoya Protocol are additionally required to quantify metrics related to providing, accessing, using, and monitoring their genetic resources.

As more countries ratify the Nagoya Protocol, many states have also established their own similar guidelines or regulations. Access to most of these governmental policies can easily be obtained through the ABS Clearing-House website (Table 1). These systems have led to the wide dissemination of related guidelines within global scientific communities. For example, the code of conduct and best practice of the Global Genome Biodiversity Network (GGBN) was modeled after the Nagoya Protocol on ABS (GGBN Guidance, 2015). The World Federation for Culture Collections (WFCC) has declared that the process of isolation, handling, storage, and distribution of microorganisms and cell cultures must be carried out safely and in compliance with relevant legislation, regulation, and international conventions (see WFCC website in Table 1). The Microbial Resource Research Infrastructure (MIRRI) program has developed strategies and tools to comply with the Nagoya Protocol and established a best practice manual based on ABS (Verkley et al., 2016). An increasing number of universities and research institutions have begun to prepare policies to accompany their countries' guidelines.

Like every other international treaty, the Nagoya Protocol is imperfect. The scientific community has raised objections to several aspects of the CBD. A recent paper published in Science, which gathered signatures of 172 scientists from 35 countries, listed the obstacles that the CBD imposes on research, and stated emphatically that scientists cannot conduct biodiversity research unless they have access to the resources they seek to study, and the ability to share those resources and their expertise among countries (Prathapan et al., 2018). The authors further urged the Conference of the Parties of the CBD to recognize the problem and to establish legal mechanisms to enable biodiversity research of relevance to conservation (Prathapan et al., 2018). In popular commentary following publication of this article, news articles identified that country frameworks and legal facility buildings to implement the Nagoya Protocol are key problems (Prathapan et al., 2018; Pisupati, 2018). Despite the positive intentions of the Nagoya Protocol, vague definitions of genetic resources, lack of legal clarity and coordination in most of the countries, and complex regulations affecting the transfer of biological material still plague its implementation (Neumann et al., 2017; Blasiak et al., 2018; Prathapan et al., 2018). Research utilizing foreign genetic resources faces increased hurdles. Specifically, international collaboration usu- 
ally requires transfer of samples, which is complicated to implement under the Nagoya Protocol. Nevertheless, it is ultimately the responsibility of "users", namely the scientists themselves, to follow international treaties and laws of foreign countries. Moreover, the organizations that employ scientists should supervise scientists' behavior and protect scientists. We recommend that universities and research institutions seek information regarding the CBD and the Nagoya Protocol and consider building their own in-house best practice rules accordingly.

\section{Nagoya Protocol with the Ocean Drilling Program}

\subsection{Utilization of genetic resources in ocean drilling science}

The marine realm comprises $70 \%$ of the surface of the biosphere and contains a rich variety of organisms, including at least 34 of the 36 living phyla, some of which are found exclusively in the oceans. Genetic resources from marine environments have been increasingly utilized, with applications in over 18000 natural products (Arrieta et al., 2010). Furthermore, 4900 patents are associated with genes of marine organisms, with a rate of increase of $12 \%$ per year (Oldham et al., 2014). Deep seabed ecosystems and their associated genetic resources offer great scientific potential. Research activities investigating deep subseafloor genetic resources are limited by technological capacity and by the financial resources required. International scientific collaboration such as the International Ocean Discovery Program (IODP) provides opportunities to access and take measurements of the deep subseafloor (Table 1).

The biosphere beneath the water column of the ocean was revealed to biologists after a successful expedition, Leg 201 of the Ocean Drilling Program (ODP). Research conducted on this expedition revealed the existence of a metabolic microbial ecosystem on the deep subseafloor (D'Hondt et al., $2003,2004)$. Since then, scientists have progressively revealed more of the significant biomass, biodiversity, and functions of microbial cells in the deep biosphere, with scientific publications on the topic increasing annually (Parkes et al., 1994; D'Hondt et al., 2004; Lipp et al., 2008; Kallmeyer et al., 2012). Conducting research on genetic resources, including through the application of biotechnology, is considered "utilization of genetic resources", according to Article 2 of the Nagoya Protocol (Table 1). "Biotechnology", as defined in the convention, means any technological application that uses biological systems, living organisms, or derivatives thereof, to make or modify products or processes for a specific use (see the Nagoya Protocol website in Table 1). According to this clause, geomicrobiological research conducted by ocean drilling programs accesses and utilizes genetic resources on the subseafloor.

Utilization of core material obtained through ocean drilling as a genetic resource is technically different than other types of research and the sampling procedure is more complicated. In general, one drilling expedition can obtain hundreds of meters of core samples. In the case of microbiological research, however, specialized sampling methodologies are required because organisms and biological molecules such as DNA, RNA, and proteins can be damaged by exposure to unusual temperatures, oxidation, and air contamination during the drilling process. Therefore, DNA research requires core samples to be deep-frozen for storage, while research targeting living cells requires more complicated storage treatment of samples (e.g., anaerobic or high-pressure conditions). Moreover, the sampling process for these experiments usually requires aseptic conditions to avoid contamination. In the current and past ocean drilling programs, some expeditions have included deep biosphere research as a major component of the original proposal (expeditions listed in Table 2). In all other cases, the collection of deep biosphere samples during an expedition is contingent on the applications (sample requests) for such samples, and/or the participation of microbiologists. We surveyed accessible databases of the current and past ocean drilling programs and found that 53 expeditions (including the nine expeditions in Table 2) included microbiologists among the science party, which allowed microbiological samples to be collected during the expedition. Besides samples collected on these expeditions, as explained above, the hundreds of kilometers of split-core samples that are stored in $4^{\circ} \mathrm{C}$ refrigerated core repositories (see IODP website in Table 1) are rendered useless for microbiological research because of the severe sample condition requirements of core samples for subsequent microbiological research. In order to expand the utilization of core samples for post-cruise research, the Kochi Core Center began curating deep-frozen core samples (Masui et al., 2009). Samples from 11 drilling expeditions in the Deep BIOsphere Sample (DeepBIOS) database are available to scientists upon request (see DeepBIOS database in Table 1), while other core repositories have also stored deepfrozen core samples (see IODP website in Table 1). These samples are available to scientists by application after the expedition moratorium. Accordingly, IODP samples can be obtained in two ways: by participating in drilling expeditions and/or by requesting samples from core repositories. All core samples and sample requests are managed through a curation system run by the science operators of the IODP.

\subsection{Controversial points of the Nagoya Protocol for ocean drilling programs}

Marine scientific research, including ocean drilling, is impacted by the United Nations Convention on the Law of the Sea (UNCLOS), which outlines the extent of states' sovereignty in the sea bed and subsoil of the territorial sea, the contiguous zone, and the sovereign right of states to an exclusive economic zone (EEZ) (see UNCLOS website in Table 1). Consequently, to drill within an EEZ, scientists 
Table 2. List of ocean drilling expeditions that included deep biosphere research as a major scientific objective in their drilling proposals. Expeditions conducted by three drilling platforms from the Ocean Drilling Program, Integrated Ocean Drilling Program, and International Ocean Discovery Program are listed. EEZ: exclusive economic zone.

\begin{tabular}{|c|c|c|c|}
\hline Expeditions & Drilling vessel & Year & Drilling location \\
\hline $\begin{array}{l}\text { Leg 201: Controls on Microbial Communities in Deeply buried } \\
\text { Sediments, Eastern Equatorial Pacific and Peru }\end{array}$ & JOIDES Resolution & 2001 & EEZ \\
\hline Exp. 329: South Pacific Gyre Microbiology & JOIDES Resolution & 2006 & International waters \\
\hline $\begin{array}{l}\text { Exp. 336: Mid-Atlantic Ridge Flank Microbiology: Initiation } \\
\text { of long-term coupled microbiological, geochemical, and hydro- } \\
\text { logical experimentation within the seafloor at North Pond, west- } \\
\text { ern flank of the Mid-Atlantic Ridge }\end{array}$ & JOIDES Resolution & 2010 & International waters \\
\hline $\begin{array}{l}\text { Exp. 366: Mariana serpentinite mud volcanism: geochemical, } \\
\text { tectonic, and Biological processes }\end{array}$ & JOIDES Resolution & 2016 & International waters \\
\hline Exp. 331: Deep Hot Biosphere & Chikyu & 2010 & EEZ \\
\hline $\begin{array}{l}\text { Exp. 337: Deep Coalbed Biosphere off Shimokita: Micro- } \\
\text { bial processes and hydrocarbon system associated with deeply } \\
\text { buried coalbed in the ocean }\end{array}$ & Chikyu & 2012 & EEZ \\
\hline Exp. 370: T-Limit of the Deep Biosphere off Muroto (T-Limit) & Chikyu & 2016 & EEZ \\
\hline $\begin{array}{l}\text { Exp. 347: Baltic Sea Basin: paleoenvironmental evolution of the } \\
\text { Baltic Sea Basin through the last glacial cycle }\end{array}$ & Mission Specific & 2013 & EEZ \\
\hline $\begin{array}{l}\text { Exp. 357: Atlantis Massif Serpentinization and Life: Microbi- } \\
\text { ological, alteration, and tectono-magmatic processes in young } \\
\text { mafic and ultramafic seafloor }\end{array}$ & Mission Specific & 2015 & International waters \\
\hline
\end{tabular}

must apply for marine scientific research (MSR) clearance to the country sovereign over the EEZ, whereas drilling in international waters does not require MSR clearance. Research targeting the deep biosphere (e.g., studies of DNA diversity or cell extraction) inevitably must access genetic resources from the country of origin. Interpreting the Nagoya Protocol becomes difficult in this context because the national regulations required by the Nagoya Protocol vary according to the country of origin of the genetic resource. The current members of the IODP have different statuses with respect to their adherence to the Nagoya Protocol. Japan, India, South Korea, China, and the European Union have ratified the Nagoya Protocol; Brazil and Australia are only signatories; New Zealand and Canada are parties to the CBD but are not parties or signatories of the Nagoya Protocol; and the United States of America is not a party to the CBD. The European Union has implemented regulations, and Japan has also established a national guideline (sea EU regulation and Japanese guideline links in Table 1). Though Brazil, Australia, and New Zealand are not parties to the Nagoya Protocol, they nevertheless have individual legal frameworks to implement ABS legislation for genetic resources. Moreover, regardless of whether the users' countries have ratified the Nagoya Protocol, scientists and their collaborators working with core samples containing DNA and microbes originally extracted from ar- eas under other national jurisdictions are required to follow the regulations of the provider countries. Naturally, the same regulations apply to continental drilling programs. We summarized drilling locations of the past expeditions that comprised deep biosphere research as a major scientific object (Table 2). Five of the expeditions obtained samples from EEZs and four obtained samples from international waters. In addition, 21 of the 53 expeditions that included microbiologists in the science party conducted drilling in EEZs. Both EEZs and international waters are important for scientific reasons; sediments from EEZs are close to shore and are usually rich in organic matter, which is linked to higher microbial biomass, whereas locations further from shore, such as international waters, tend to have oxygen down through the deep sediments (Kallmeyer et al., 2012; D'Hondt et al., 2015). Roughly half of the previous drilling expeditions included deep biosphere research drilled within EEZs. Therefore, it is important for microbiologists to determine ABS regulations of the EEZ country very early in their expedition preparations.

Furthermore, the timing of the sample's extraction is also a key issue to consider. For example, core samples for analyzing DNA were obtained from EEZs of Peru and Ecuador during Leg 201 in 2002, but the Nagoya Protocol was only ratified in those countries in 2014 and 2017, respectively 
(D'Hondt et al., 2003). Peru established subsequent restrictive legislation in 2014 (https://absch.cbd.int/countries/PE/ MSR, last access: June 2018), but Ecuador, thus far, has not. Although the scope of the Nagoya Protocol is not retroactive, several countries apply its terms on benefit sharing to continuing and new uses of genetic resources. A similar example relates to core samples that were obtained in 2013 from the EEZ of Denmark and Sweden during Exp. 347. These samples were collected prior to the EU regulation of 2014 that declared the Nagoya Protocol effective (The European Parliament and the Council of the European Union, 2014). Whether the rights outlined in the Nagoya Protocol extend to past expeditions must be assessed case by case.

\subsection{Implementation of the Nagoya Protocol}

Since the Nagoya Protocol came into effect, PIC and MAT applications have been required in addition to MSR clearance when drilling occurs in another country's EEZ. Principal investigators of deep biosphere research will require assistance from the science operators of the drilling vessels due to the potentially complicated legal requirements associated with application for ABS. Countries of origin may require detailed information on access to genetic resources, namely the extraction time, drilling location, and sampling quantities, far in advance of the expedition, which burdens scientists who apply independently. Managing the utilization of the genetic resources through the IODP, however, is much simpler than gaining access. A highly advanced system has already been developed by IODP curators to manage sample requests and trace genetic resources. All core samples are identified by location and depth and provided in response to a sample request. A material transfer agreement (MTA) form is recommended to help science operators manage the transfer of biological samples. The "IODP Sample, Data and Obligation Policy" already requires the publishing of data obtained utilizing IODP samples (http://www.iodp.org/ top-resources/program-documents/policies-and-guidelines, last access: July 2018), thereby meeting the compliance obligations of the Nagoya Protocol for monitoring the utilization of genetic resources after they leave the source country. The situation of implementing the Nagoya Protocol and the time required for obtaining necessary legal clearance varies among countries. For instance, Japan's guidelines and the EU's regulations claim that no PIC is needed for scientific research of their genetic resources (see links in Table 1). India and Vietnam do not allow access to their genetic resources without prior applications to their governments (Ministry of Environment of Japan, 2018a, b). In general, it can take up to several months to obtain ABS permissions, which needs to be taken into account from the early stages of expedition planning.

\subsection{Future concerns}

Firstly, the Nagoya Protocol addresses ABS for genetic resources within national waters, while currently there is no such mechanism for genetic resources from the areas beyond national jurisdiction (ABNJs). The UN has continuously negotiated the "packaged" issue in multiple meetings including at the Biological Diversity of the ABNJ (BBNJ) Working Group (2006-2015), Preparatory Committee (2016-2017), and BBNJ treaty negotiations that began in September 2018. The reports of those meetings show that there was discussion for some form of benefit sharing for exploring genetic resources in the $\mathrm{ABNJ}$, together with management tool building (Earth Negotiations Bulletin, 2018). The conclusion of the negotiations will most likely be to develop an international legally binding instrument under the UNCLOS for the conservation and sustainable use of marine biological diversity of ABNJ (United Nations Environment Programme, 2016). Therefore, the future scope of the CBD and the Nagoya Protocol may be extended to include the ABNJ of the UNCLOS, and such a global ABS measure would conceivably affect all scientific drilling expeditions (Rochette et al., 2015). Regardless of whether drilling occurs in the EEZ or in the ABNJ, researchers will need to obtain some form of consent to conduct deep biosphere research prior to undertaking expeditions, and this consent will require benefit-sharing agreements for after the research is completed. Ultimately, principal investigators of deep biosphere research will have to engage with global ABS regulations, including the Nagoya Protocol and the new treaty on the ABNJ of the UNCLOS.

Secondly, questions remain regarding the types of information on genetic resources that might be included in the scope of the Nagoya Protocol. Nucleic acid sequence reads and associated data as well as information on sequence assembly, annotation, and genetic mapping, which may describe up to an organism's whole genome, are suggested for inclusion as genetic resources, according to the report of the Ad Hoc Technical Expert Group on Digital Sequence Information on Genetic Resources (2018). Furthermore, metagenome sequencing of the deep seabed or sea water could be included in the scope of the Nagoya Protocol. In response to this possible hurdle, the Alliance of Science Organizations in Germany strongly cautioned against expanding the scope of the Nagoya Protocol to include digital sequence information (Alliance of Science Organizations in Germany, 2018). The massive growth in our life science knowledge base depends largely on the free and open availability of digital sequence information. Restriction of access to digital sequence information would significantly impair scientific progress. It is important for scientists to be aware of political limitations on their research activities. 


\section{Tentative implementation in JAMSTEC}

Scientists of the Japan Agency for Marine-Earth Science and Technology (JAMSTEC) are told to consult the administration office nearly 2 years prior to conducting field research in EEZs or on land of other countries. The administration office (and outsourcing law office as needed) assists scientists in obtaining permissions for MSR, ABS, or any other necessary legislation. In addition to its role as a "user" of genetic resources, JAMSTEC also functions as a "provider" of such resources. JAMSTEC's drilling vessel (DV) Chikyu has riser drilling equipment, which enables it to drill deeper than any other scientific drilling vessel. Chikyu has served as an official vessel in the IODP since 2007. To date, all IODP expeditions conducted by DV Chikyu drilled within the Japanese EEZ. Genetic resources extracted by Chikyu have been distributed worldwide under the IODP framework. Samples have been utilized for onboard distribution, and through secondary distribution in response to sample requests to the Kochi Core Center (see DeepBIOS website in Table 1). To adhere to the Nagoya Protocol, JAMSTEC established the Guidance on Access and Benefit Sharing on Subseafloor Genetic Resources from DV Chikyu and drafted a MTA for IODP expeditions in 2016. Ownership of the samples was claimed by JAMSTEC, and agreements on utilization and related intellectual property were established in the MTA. The IODP manages distribution and utilization of the core samples under the supervision of its "IODP Sample, Data, and Obligation Policy". The MTA for genetic resources taken by DV Chikyu was drafted to meet the requirements of stakeholders of both the IODP and the Nagoya Protocol frameworks. In its guideline, Japan has decided that no PIC is required for accessing genetic resources from Japan, and the Japanese government encourages research institutions to take measures to govern their own genetic resources, in a similar vein to the EU regulation (see links to Japanese guidelines and EU regulation in Table 1). JAMSTEC will seek PIC when DV Chikyu drills in other countries' territorial waters or EEZs and will take any additional action required by their research partners. This scenario will necessitate further contracts between JAMSTEC and foreign scientists regarding distribution of the core samples for biological research.

\section{Summary}

Scientific ocean drilling began as a research tool for fundamental geological research and has been crucial for attaining significant geological and geochemical findings as well as technological developments. Deep biosphere research developed quite recently but has grown significantly in recent decades. As a result of data collected from international ocean drilling expeditions and data benefit sharing, considerable achievements have been made in understanding the extensive subseafloor biosphere. The Nagoya Protocol is an international agreement that aims to guide countries in developing standard protocols and protections for accessing biological materials, and sharing the benefits derived from their utilization. Since its commencement, the Nagoya Protocol has placed international biological research, especially fieldwork, under greater political scrutiny and increased its complexity due to the variation in implementation between nations. Researchers and science operators must study and comply with permitting requirements for the countries in whose EEZ they plan to drill. Updated information on emerging legislation and regulations applicable to genetic resource usage is available for curators and staff participating in scientific drilling programs on the ABS Clearing-House website (Table 1). Crucially, potential users, particularly microbiologists, must communicate with officials responsible for implementation of ocean drilling programs to ensure that their requirements for necessary ABS measures and the related scientific importance are clear, protected, and attainable.

We will monitor the progress of the UN's new treaty regarding $\mathrm{ABNJ}$ and report new information in future articles as it becomes available.

Data availability. Data are available on request from the corresponding author. 
Appendix A: List of acronyms

$\begin{array}{ll}\text { ABNJ } & \text { Area beyond the national jurisdiction } \\ \text { ABS } & \text { Access and benefit sharing } \\ \text { BBNJ } & \text { Biodiversity beyond national jurisdiction } \\ \text { CBD } & \text { Convention on Biological Diversity } \\ \text { EEZ } & \text { Exclusive economic zone } \\ \text { EU } & \text { European Union } \\ \text { IODP } & \begin{array}{l}\text { International Ocean Drilling Program/Inter- } \\ \text { national Ocean Discovery Program }\end{array} \\ \text { MAT } & \text { Mutually agreed terms } \\ \text { MTA } & \text { Material transfer agreement } \\ \text { NP } & \text { Nagoya Protocol } \\ \text { ODP } & \text { Ocean Drilling Program } \\ \text { PIC } & \text { Prior informed consent } \\ \text { UN } & \text { United Nations } \\ \text { UNCLOS } & \text { United Nations Convention on the Law of the } \\ & \text { Sea }\end{array}$


Author contributions. NX designed the study and wrote the initial paper. All other authors reviewed the paper and approved the final version.

Competing interests. The authors declare that they have no conflict of interest.

Acknowledgements. The authors gratefully acknowledge ABS Task Force Team for Academia, National Institute of Genetics Japan, for their helpful advice.

Edited by: Jan Behrmann

Reviewed by: two anonymous referees

\section{References}

Ad Hoc Technical Expert Group on Digital Sequence Information on Genetic Resources: Report of the ad hoc technical expert group on digital sequence information on genetic resources, available at: https://www.cbd.int/doc/c/4f53/a660/ 20273cadac313787b058a7b6/dsi-ahteg-2018-01-04-en.pdf (last access: September 2018), 2018.

Alliance of Science Organisations in Germary: The Alliance of Science Organisations in Germany sees open access to digital sequence information at risks, available at: https://www.wissenschaftsrat.de/download/archiv/Allianz DSI_EN_090218.pdf (last access: September 2018), 2018.

Arrieta, J. M., Arnaud-Haond S., and Duarte, C. M., What lies underneath: Conserving the ocean's genetic resources, P. Natl. Acad. Sci., 107, 18318-18324, 2010.

Blasiak, R., Jouffray, J. B., Wabnitz, C. C. C., Sundström, E., and Österblom, H.: Corporate control and global governance of marine genetic resources, Sci. Adv., 4, 5237, https://doi.org/10.1126/sciadv.aar5237, 2018.

D’Hondt, S., Jørgensen, B. B., Miller, D. J., and Shipboard Scientific Party: Proceedings of the Ocean Drilling Program, Initial Reports Volume 201, 2003.

D’Hondt, S., Jørgensen, B. B., Miller, D. J., Batzke, A., Blake, R., Cragg, B. A., Cypionka, H., Dickens, G. R., Ferdelman, T., Hinrichs, K-U., Holm, N. G., Mitterer, R., Spivack, A., Wang, G., Bekins, B., Engelen, B., Ford, K., Gettemy, G., Rutherford, S. D., Sass, H., Skibeck, C. G., Aiello, I. W., Guerin, G., House, C., Inagaki, F., Meister, P., Naehr, T., Niitsuma, S., Parkes, R. J., Schippers, A., Smith, D. C., Teske, A., Wiegel, J., Padilla, C. N., and Acosta, J. L. S.: Distributions of metabolic activities in deep subseafloor sediments, Science, 306, 2216-2200, 2004.

D’Hondt, S., Inagaki, F., Zarikian, C. A., Abrams, L. J., Dubois, N., Engelhardt, T., Evans, H., Ferdelman, T., Gribsholt, B., Harris, R. N., Hoppie, B. W., Hyun, J., Kallmeyer, J., Kim, J., Lynch, J. E., Mckinley, C., Mitsunobu, S., Morono, Y., Murray, R. W., Pockalny, R., Sauvage, J., Shimono, T., Shiraishi, F., Smich, D. C., Smith-Duque, C. E., Spivack, A., Steinsbu, B. O., Suzuki, Y., Szpak, M., Toffin, L., Uramoto, G., Yamaguchi, Y. T., Zhang, G., Zhang, X., and Ziebis, W.: Presence of oxygen and aerobic communities from sea floor to basement in deep-sea sediments, Nature Geosci., 8, 299-304, 2015.
Earth Negotiations Bulletion: BBNJ IGC 1 \#3, 25-171, available at: http://enb.iisd.org/oceans/bbnj/igc1/ (last access: September 2018), 2018.

Global Genome Biodiversity Network (GGBN) Guidance: Best Practice for Access and Benefit-Sharing and Code of Conduct, available at: https://wiki.ggbn.org/ggbn/Documents\#Access_ and_Benefit_Sharing (last access: September 2018), 2015.

Kallmeyer, J., Pockalny, R., Adhikari, R. R., Smith, D. C., and D'Hondt, S.: Global distribution of microbial abundance and biomass in subseafloor sediment, P. Natl. Acad. Sci. USA, 109, 16213-16216, 2012.

Lipp, J. S., Morono, Y., Inagaki, F., and Hinrichs, K.-U.: Significant contribution of Archaea to extant biomass in marine subsurface sediment, Nature, 454, 991-994, 2008.

Masui, N., Morono, Y., and Inagaki, F.: Bio-Archive Core Storage and Subsampling Procedure for Subseafloor Molecular Biological Research, Sci. Dril., 8, 35-37, https://doi.org/10.2204/iodp.sd.8.05.2009, 2009.

Ministry of the Environment of Japan: Vietnam ABS Decree, avail 2018a (in Japanese).

Ministry of the Environment of Japan: Indian Biodiversity Acition, 2018b (in Japanese).

Neumann, D., Borisenko, A. V., Coddington, J. A., Hauser, C. L., Bulter, C. R., Casino, A., Vogel, J. C., Haszprunar, G., and Giere, P.: Global biodiversity research tied up by juridical interpretations of access and benefit sharing, Org. Divers. Evol., 18, 1-12, 2017.

Ocean Drilling Program Leg. 201 Preliminary Report: Controls on Microbial Communities in Deeply Buried Sediments, Easter Equatorial Pacific and Peru Margin, 2002.

Oldham, P., Hall, S., Barnes, C., Oldham, C., Cutter, M., Burns, N., and Kindness, L.: Valuing the Deep: Marine Genetic Resources in Areas Beyond National Jurisdiction, One World Analytics, 2014.

Parkes, R. J., Cragg, B. A., Bale, S. J., Getliff, J. M., Goodman, K., Rochelle, P. A., Fry, J. C., Weightman, A. J., and Harvey, S. M.: Deep bacterial biosphere in Pacific Ocean sediments, Nature, 371, 410-413, 1994.

Pisupati, B.: [Commentary] CBD: Can the cure kill?, MONGABAY, available at: https://india.mongabay.com/2018/07/17/ commentary-cbd-can-the-cure-kill/ (last access: October 2018), 2018.

Prathapan, K. D., Pethiyagoda, R., Bawa, K. S., Raven, P. H., Rajan, P. D., and 172 co-signatories from 35 cuntries: When the cure kills-CBD limits biodiversity research, Science, 360, 1405-1406, 2018.

Rochette, J., Wright, G., Gjerde, K. M., Greiber, T., Unger, S., and Spadone, A.: A new Chapter for the High Seas?, Institute for Advanced Sustainability Studies (IASS) Working Paper, 2015.

Secretariat of the Convention on Biological Diversity: Bonn Guidelines on Access to Genetic Resources and Fair and EquiTable Sharing of the Benefits Arising out of their Utilization, ISBN 90-807-2255-7, 2002.

Secretariat of the Convention on Biological Diversity: Sustaining life on Earth, How the Convention on Biological Diversity promotes nature and human well-being, ISBN 90-807-1904-1, 2010.

The ABS Guidelines in Japan: http://www.env.go.jp/nature/ biodic-abs/english.html (last access: September 2018), 2017. 
The Alliance of Science, Press release of the Alliance of Science Organisations in Germany, available at: https://www.fraunhofer.de/en/press/researchnews/2018/February/the-alliance-of-science-organisationsin-germany-sees-open-access-to-digital-sequence-informationat-risks.html (last access: September 2018), 2018.

The European Parliament and the Council of the European Union: Regulation (EU) No 511 of THE EUROPEAN PARLIAMENT AND THE COUNCIL OF THE EUROPEAN UNION on compliance measures for users from the Nagoya Protocol on Access to Genetic Resources and the Fair and EquiTable Sharing of Benefits Arising from their Utilization in the Union, 2014.

United National Environment Programme: Diversity, Secretariat of the Convention on Biological Diversity, available at: https:// www.cbd.int/convention/text/ (last access: October 2018), 2011.
United Nations Convention on the Law of the Sea: http://www.un.org/Depts/los/convention_agreements/texts/ unclos/UNCLOS-TOC.htm (last access: September 2018), 1982.

United Nations Environment Programme: Regional Seas Programmes and other UNEP Activities Relevant to Marine Biodiversity in Areas beyond National Jurisdiction, available at: https://www.cbd.int/doc/publications/cbd-sustain-en (last access: September 2018), 2016.

Verkley G., Martin D., and Smith D.: Microbial Resource Research Infrastructure, Best Practice Manual on Access and Benefit Sharing, Version 1.0, Microbial Resource Research Infrastruture (MIRRI), 2016. 